\title{
Research on the Influence Mechanism of the High-Steep Slope on the Deformation Characteristics of Bridge Substructure
}

\author{
Yufang Zhang $\mathbb{D}^{1},{ }^{1}$ Hongyu Liu $\mathbb{D},^{2}$ Jian Li $\mathbb{D},{ }^{1}$ Jiaming Li $\mathbb{D},{ }^{1}$ Qidi Huang $\mathbb{D},{ }^{1}$ \\ and Xianjie $\mathrm{Ma} \mathbb{D D}^{2}$ \\ ${ }^{1}$ Railway Engineering Research Institute, China Academy of Railway Sciences Group Co. Ltd.,, Beijing 100081, China \\ ${ }^{2}$ School of Energy and Mining Engineering, China University of Mining and Technology (Beijing), Beijing 100083, China \\ Correspondence should be addressed to Jian Li; 118838978987@126.com
}

Received 15 June 2021; Accepted 14 August 2021; Published 1 September 2021

Academic Editor: Dawei Yin

Copyright (C) 2021 Yufang Zhang et al. This is an open access article distributed under the Creative Commons Attribution License, which permits unrestricted use, distribution, and reproduction in any medium, provided the original work is properly cited.

With the development of the Chinese railway, the high-steep slope is irreversible to be faced; especially under severe conditions such as heavy rainfall and earthquake, this kind of slope is prone to geological disasters, which seriously affects the safety and stability of the bridge substructure. Aiming to this, long-term monitorization and numerical analysis were carried out in this research, and the influence mechanism of the high-steep slopes on the stress and deformation characteristics of the bridge structure was studied. The research results show that under the effect of rainfall and earthquake, the original stress balance in the high-steep slope is broken, and the possibility of landslide thrust increases; under the comprehensive impact of residual landslide thrust, traction force at slope foot, vertical gravity of bridge slab and vehicle, and the bridge cap will deform. Besides, the deformation of the bridge pier exceeds the allowable lateral displacement of the top of the bridge pier, reaching $111.7 \% \sim 112.4 \%$ of the limit, which seriously affects the stability of the bridge structure and the safety of the railway service. Therefore, by increasing the support strength of the slope foot and the diameter of the bridge pile foundation, the traction force of the slope foot can be reduced, and the sliding resistance of the bridge pile foundation can be improved so as the safety of the bridge structure can be promoted.

\section{Introduction}

Considering the railway alignment and the natural environment, many railways have to be built along high-steep slopes during the development of the Chinese railway; at this time, the horizontal force of the rock and soil will be subjected to the substructure of the bridge. Besides, because the substructure of the bridge is designed to mainly ensure vertical supportability, the horizontal bearing capacity is limited, and the deformation of the pier foundation needs to be strictly controlled. Especially under severe conditions such as the rainstorm and earthquake, the high-steep slope is prone to occur whole sliding and topsoil sliding and collapse, which seriously affects the safety and stability of the substructure of the bridge [1-5].

Compared with flat areas, the substructure of bridges on a high-steep slope is more complicated and has many differences in bearing mechanism and stress conditions. Given its stress characteristics, the influence of the vertical load on the substructure of the bridge was studied from the aspect of the load effect of the slope soil, the bridge substructure the bearing characteristics of the slope, and the stress-strain relationship [6-12].

The loading mechanism of the bridge substructure is studied mainly by using the methods of theoretical analysis, numerical simulation, and model experiment. After being subjected to the horizontal loading, the deformation characteristics and the relationship between internal stress and deformation of the bridge substructure were studied [13-19].

Although there has been much relevant research, they just carry out the qualitative investigation from the aspects of deformation characteristics and influence mechanism, and the quantitative research is still limited.

In this paper, based on a railway, the influence mechanism of the high-steep slopes on the stress and deformation characteristics of the bridge substructure was studied. 

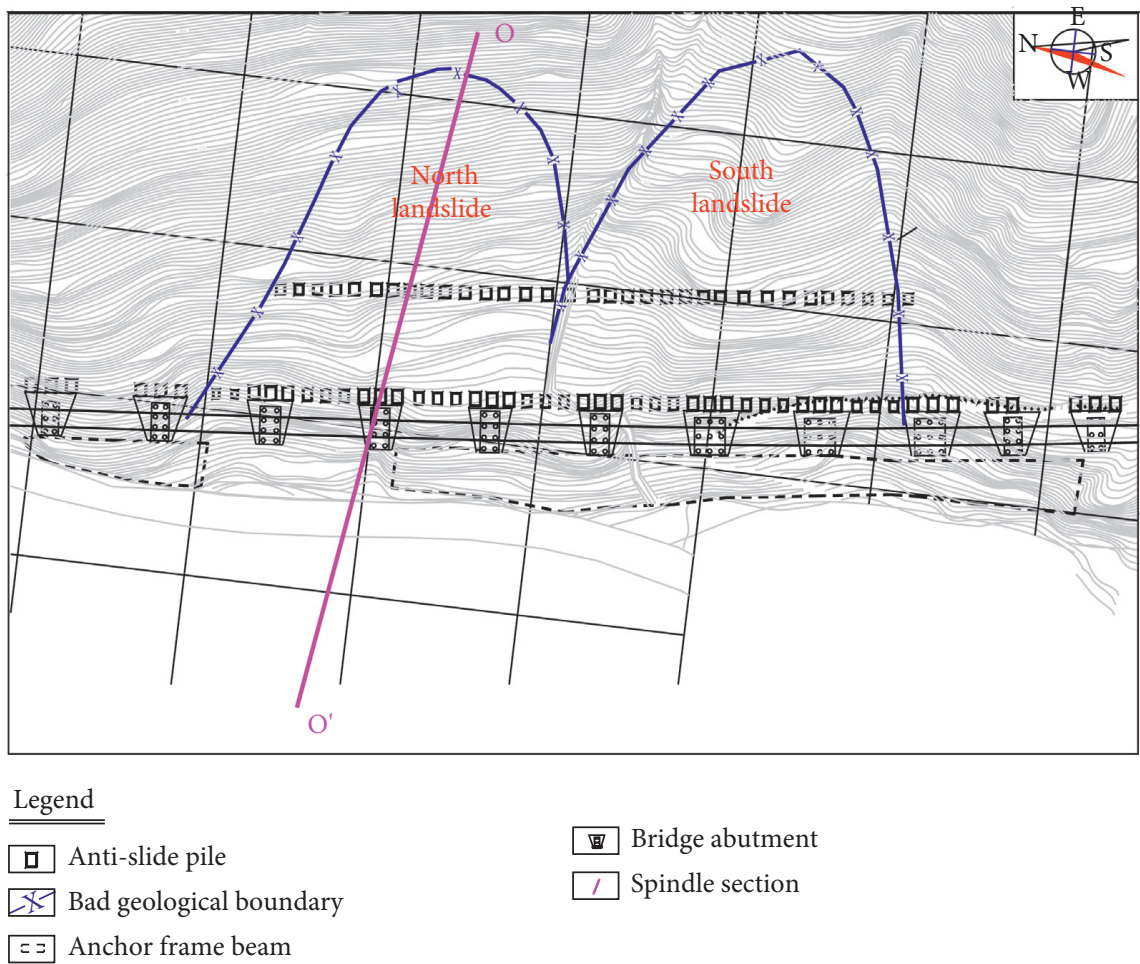

Bridge abutment

Spindle section

FIgURE 1: The engineering geological plan of landslide.

\section{Overview of Long-Term Monitorization}

2.1. The Introduction of the Project Site. The bridge structure is located at the foot of the steep slope, which is in the range of the alluvial fan accumulation area and the river terrace area, and the terrain in this area is relatively flat and is high in the east (on the side of the mountain) and low in the west (on the side of the river), forming deep gullies. In order to reduce the threat of high-steep slopes to the bridge substructure, the antislide piles are mainly adopted as protective measures as shown in Figures 1 and 2.

2.2. Stability Evaluation of High-Steep Slope. As shown in Figure 3, the landslide scale is relatively large and composed of two landslides in the north and south directions. For the north landslide, the direction of the main axis is $\mathrm{NW}^{\circ} 1^{\circ}$, the longitudinal slope is about $42^{\circ}$, the length of the main axis is about $130 \mathrm{~m}$, and the width of the landslide bottom is about $202 \mathrm{~m}$. From the aspect of geomorphology, the landslide has the potential of collapse, and the sliding surface is steeper than the accumulation layer; besides, the rock and soil are unevenly distributed, and the weak rock and soil are easy to be weathered and softened by water.

Under the intense effect of the geological structure, the rock mass is broken, and the joint fissures are more developed in the shape of "X," and the joint surface is mostly orthogonal to the layer. The joint surface is relatively straight, the joints of the earth surface slightly open $(1 \sim$ $5 \mathrm{~mm}$ ) with the space of $0.3 \sim 1 \mathrm{~m}$, the sandstone spacing is large, the slate spacing is small, and the rocks mostly disintegrate along the joint surface, forming dangerous rocks on the cliff.

According to the on-site survey, it is analyzed that the high-steep slope has a significant impact on the bridge substructure, and its instability may endanger the bridge substructure under the condition of rainfall or earthquake.

\section{Long-Term Monitorization and Analysis of the Influence of High-Steep Slope on Bridge Substructure}

\subsection{The Design of the Long-Term Monitorization}

3.1.1. Monitorization Scheme. In the field, the deep displacement of the slope, the deformation and stress of the antislide pile, and the stress of the bridge pile foundation are all monitored.

3.1.2. Rainfall Condition. The landslide is located in the alpine climate zone in northwestern Sichuan, where the annual precipitation is $500-900 \mathrm{~mm}$, and the 30 -year average annual precipitation is $731.226 \mathrm{~mm}$. The rainy season is from early June to mid-September, accounting for about $50 \%$ to $60 \%$ of the annual rainfall.

3.1.3. Earthquake Condition. On May 12, 2008, an M8.8 earthquake occurred in Wenchuan County, Aba Prefecture, Sichuan Province, and an M7.0 earthquake occurred in Jiuzhaigou County, Aba Prefecture, Sichuan Province, on 


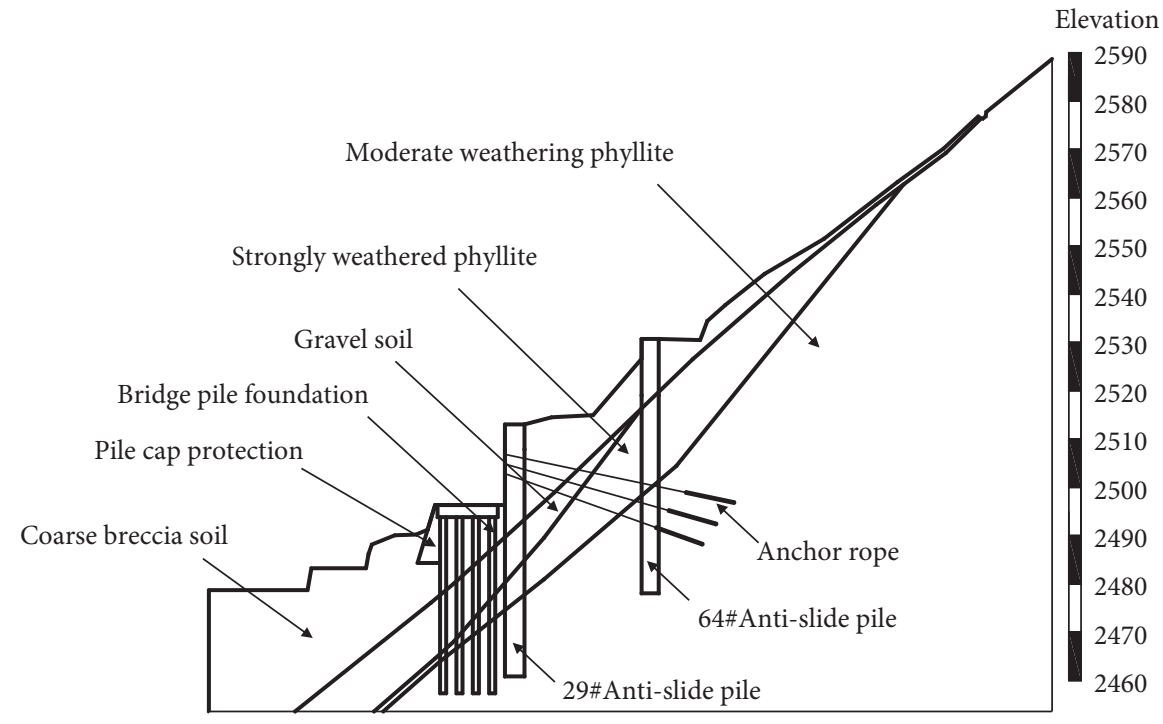

FIGURE 2: Engineering geological section of landslide.

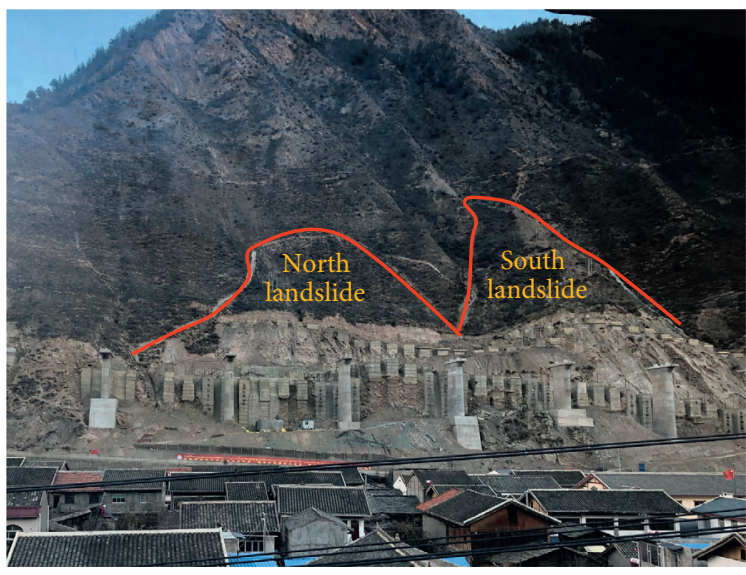

Figure 3: The illustration of the landslide body.

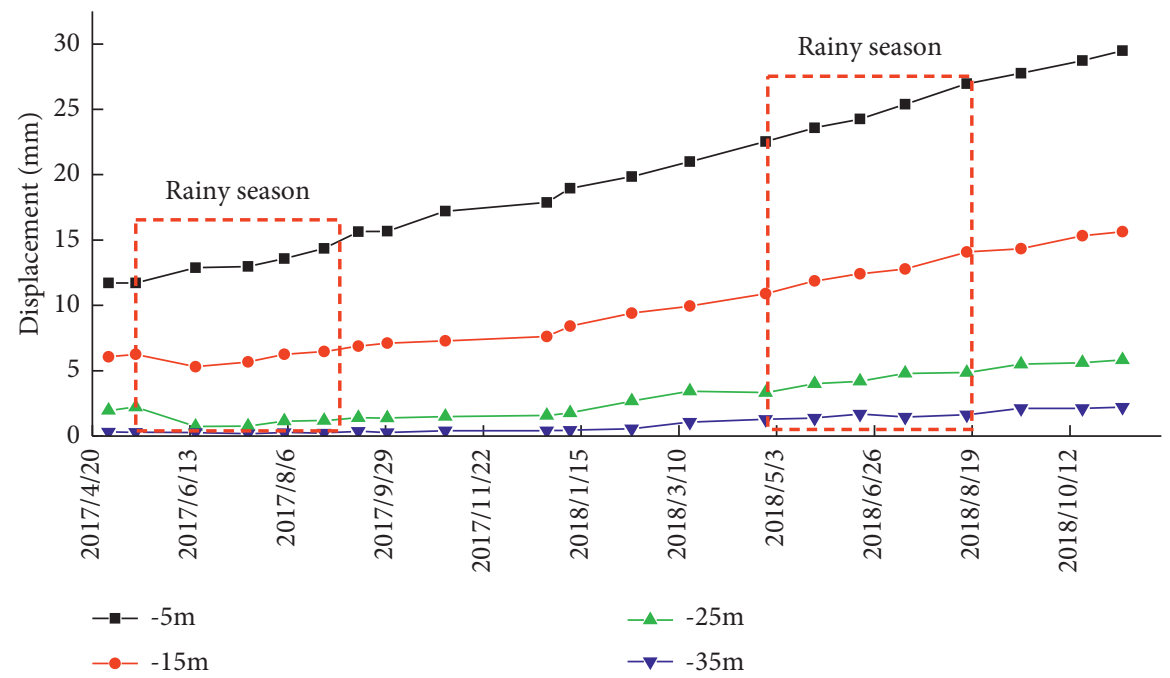

Figure 4: Displacement curve of 29\# antislide pile at same depths during the rainy season. 


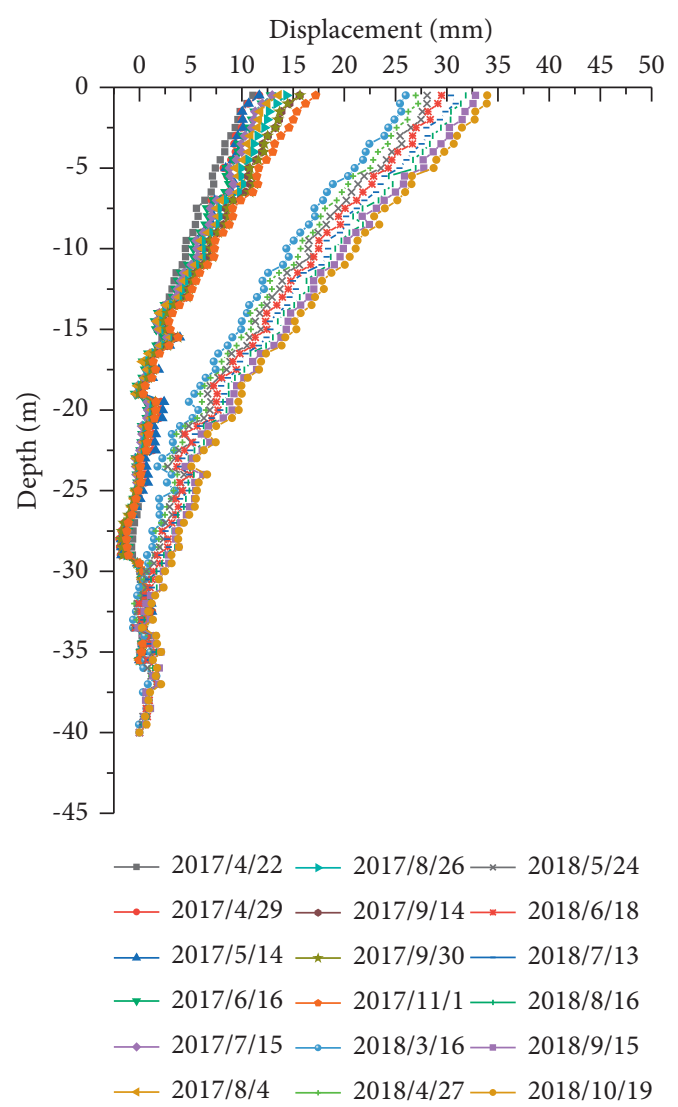

Figure 5: Displacement curve of 29\# antislide pile at different depths during the rainy season.

August 8, 2017. The intensity of the area where the landslide is located is 6.0 .

\subsection{Long-Term Monitorization and Analysis of the Impact of} High-Steep Slopes on Bridge Engineering under Rainfall Conditions. As shown in Figure 4, in the rainy season, the 29\# antislide pile exhibited the same deformation characteristics at different depths; the displacement of the antislide pile continuously increases, and the maximum deformation reached $5 \mathrm{~mm}$ at the depth of $5 \mathrm{~m}$.

As shown in Figure 5, it can also be found that the 29\# antislide pile exhibited the trend of the relative displacement decreasing with the depth, and the maximum deformation of the surface was $6 \mathrm{~mm}$, indicating that the adoption of the antislide pile is effective, and the high-steep slope is in a stable state under normal rainfall condition.

As shown in Figure 6, in the rainy season, the body stress on the side of the pile showed the shape of " $\varepsilon$ " in overall and an increasing trend. The stress reached the maximum at $19 \mathrm{~m}$, with an average daily increase of $0.12 \mathrm{MPa}$; this low growth rate indicates that the antislide pile has a good supporting effect when the pile stress is increased by the increased slope thrust under the effect of rainfall.

As shown in Figure 7, in the rainy season, the stress on the pile foundation of the $4 \#$ bridge pier generally showed a gentle increasing trend with an average daily increase of $0.012 \mathrm{MPa}$ and reached the maximum at $10 \mathrm{~m}$; besides,

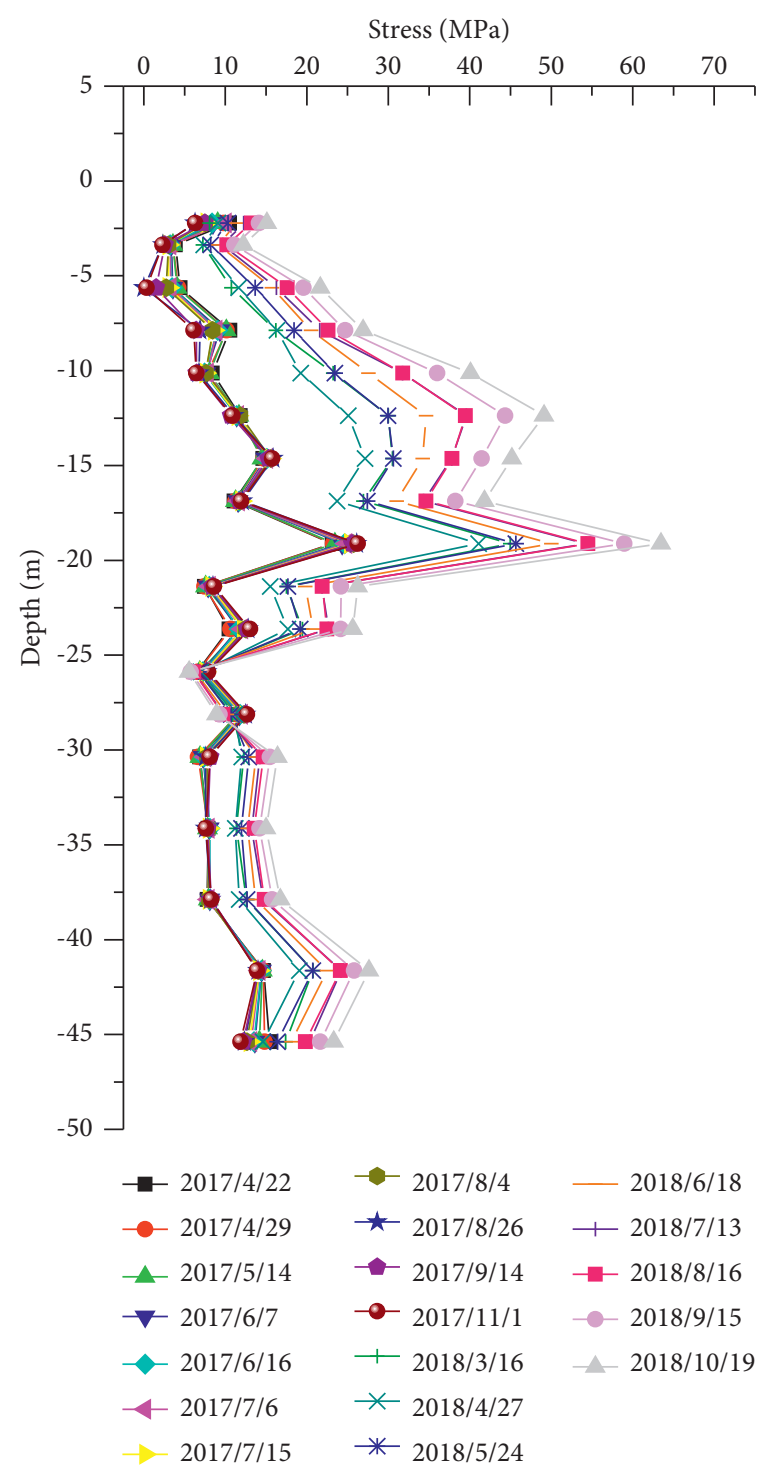

FIgURE 6: Body stress of 29\# antislide pile during the rainy season.

compared with the 29\# antislide pile, its growth rate was reduced by $90 \%$. At the same time, the pile foundation showed a stress reversal point near the soil-rock interface, where the stress is $-4.37 \mathrm{MPa}$, and its value increased with the rainfall; this indicates that due to the existence of the antislide pile, the remaining landslide thrust subjected to the bridge pile foundation is significantly reduced, and the bridge pile foundation is nearly not affected.

In a regular rainfall year, the support structure of the bridge can guarantee that the increased landslide thrust has no significant impact on the stress of the bridge structure. However, it cannot be assured under the condition of extreme rainfall or continuous heavy rainfall.

3.3. Long-Term Monitorization and Analysis of the Influence of High-Steep Slopes on Bridge Engineering under Earthquake Condition. As shown in Figure 8, during the earthquake, the 29\# antislide pile generally showed the characteristics of 


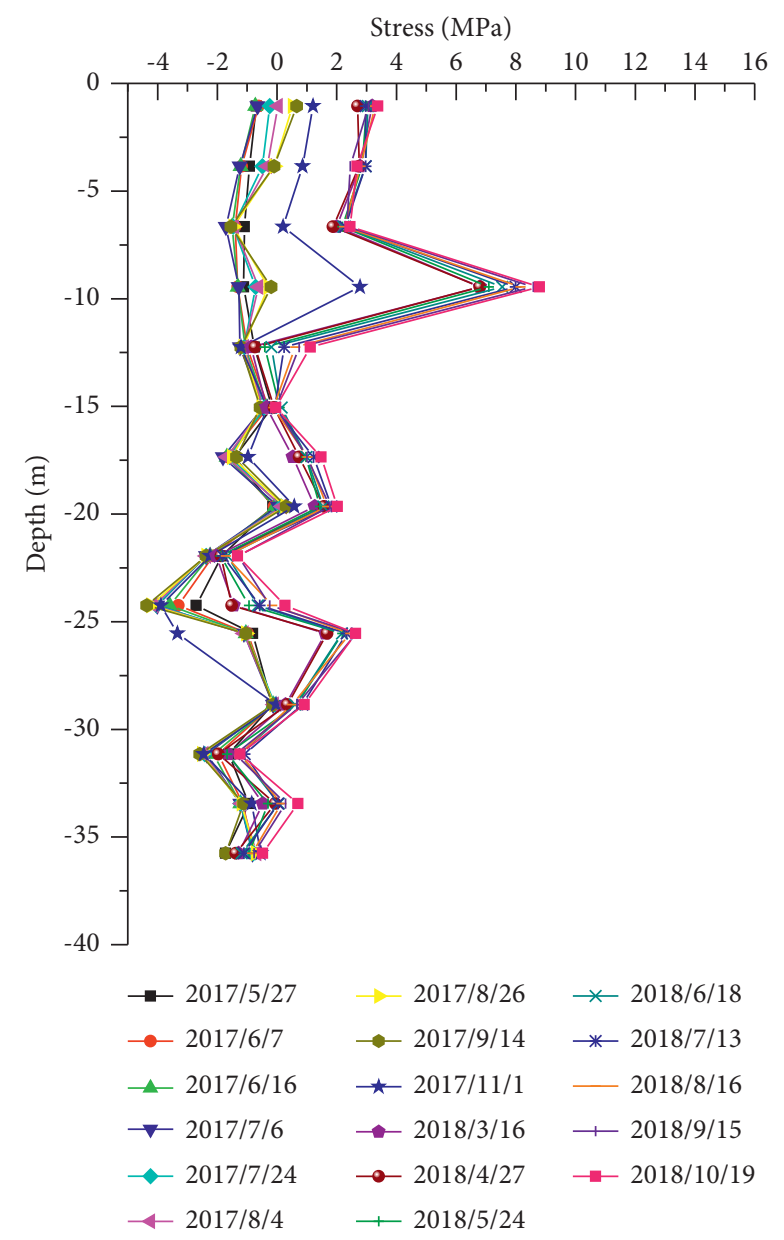

FIgURE 7: 4\# stress curve of bridge pier pile foundation at different depths.

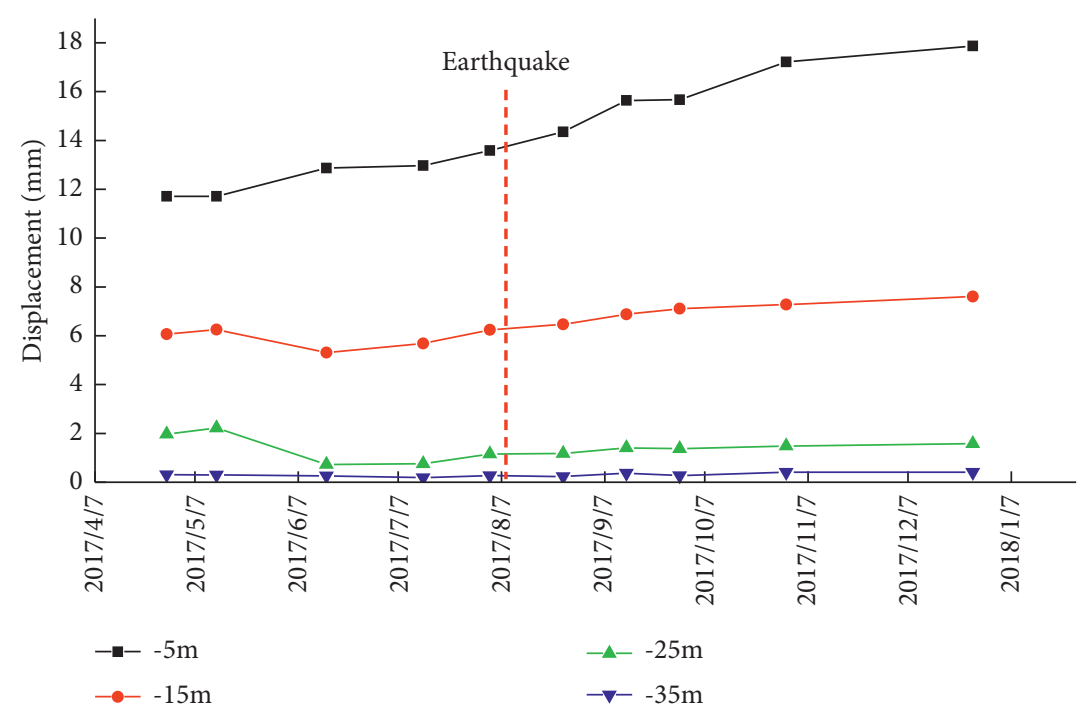

FIGURE 8: Displacement curve of 29\# antislide pile at same depths during the earthquake.

relative displacement decreasing with the depth, but its variation became gentle from the depth of $25 \mathrm{~m}$ to the depth of $35 \mathrm{~m}$. After the earthquake, the displacement did not change, indicating that the earthquake with a magnitude of
6.0 does not cause a significant impact on the high-steep slope, and the slope can keep stable.

As shown in Figure 9, the slope was disturbed by the earthquake, and the 29\# side inclined hole produced a 


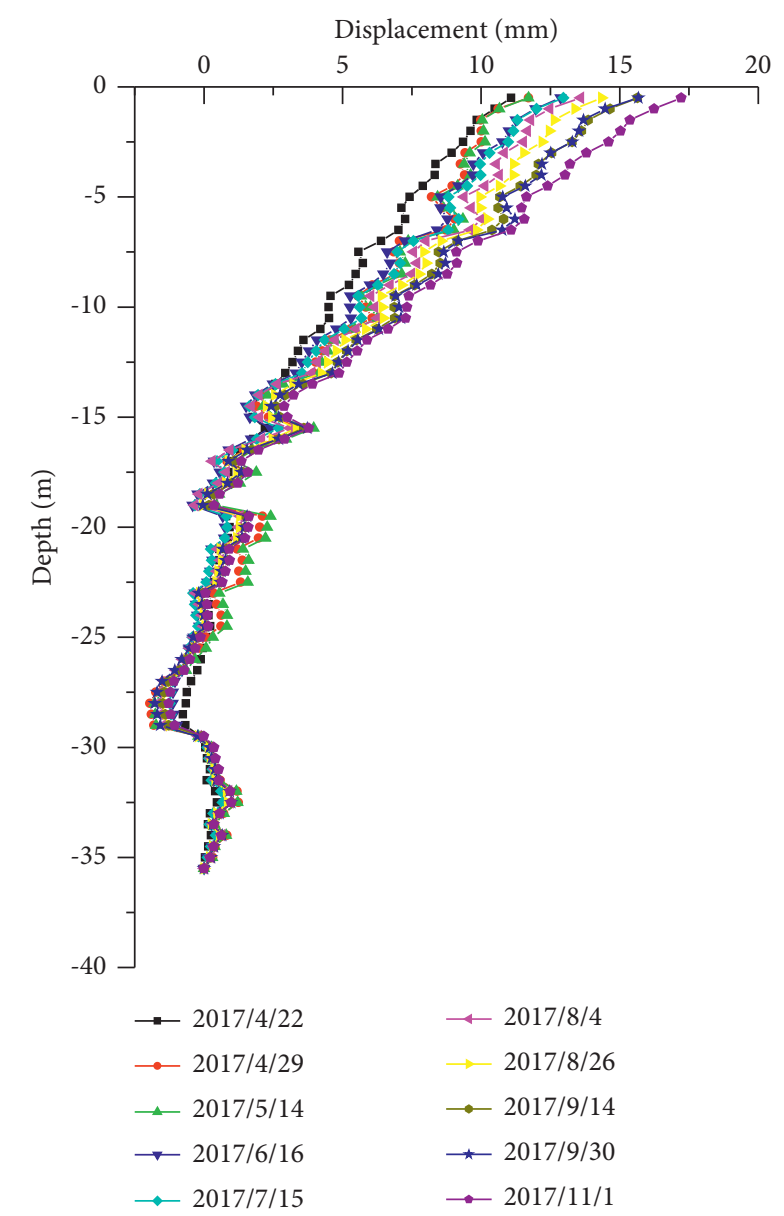

Figure 9: Displacement curve of 29\# antislide pile at different depths during the earthquake.

maximum displacement of $0.8 \mathrm{~mm}$; this small displacement suggests that the slope body is in a stable state as a whole.

As shown in Figure 10, under the effect of the earthquake, the body stress of the antislide piles generally showed a gradually increasing trend. After the earthquake, the daily stress increment was $37 \mathrm{kPa}$, and the pile did not change significantly, indicating that the stress of the antislide piles plays a good supporting role and is in a stable state.

As shown in Figure 11, during the earthquake, the stress characteristics of the $4 \#$ bridge pier pile foundation were similar to those in the rainy season, except that the stress was relatively small; this indicates that due to the antislide pile, the remaining landslide thrust caused by the loosening of the rock and soil caused has been significantly reduced and has no obvious impact on the bridge pile foundation.

Under the influence of an earthquake with a magnitude of 6 , the increased landslide thrust of the high-steep slope does not have a significant impact on the stress of the bridge structure because of the support of the bridge structure.

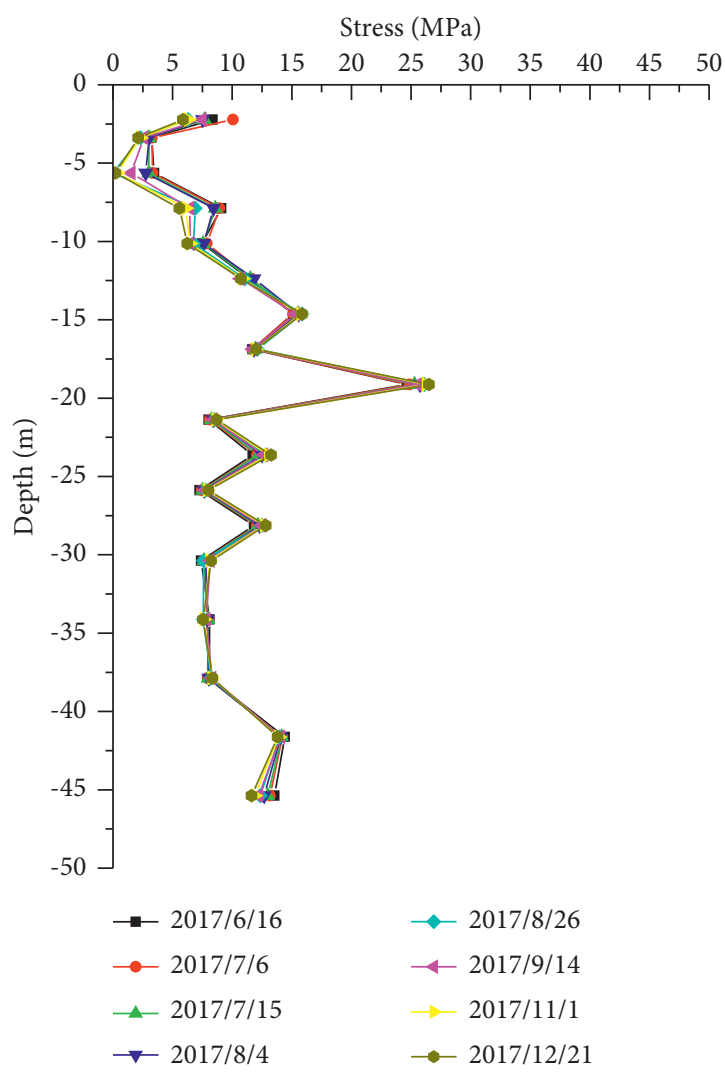

FIgURE 10: The body stress of $29 \#$ antislide pile during the earthquake.

However, the situation may be different under extreme earthquake conditions.

\section{Numerical Analysis of the Influence of High- Steep Slope on Bridge Substructure}

\subsection{The Numerical Simulation}

4.1.1. The Establishment of the Model. In this research, FLAC3D software was adopted for numerical calculation and analysis. During modelling, the soil adopts the Mohr-Coulomb constitutive; the pile cap and the antislide pile are simulated by solid elements; the pile foundation is simulated by the pile element; and the anchor cable is simulated by the cable element; besides, the normal displacement is restricted, the bottom is fixed, but the slope surface is free, as shown in Figure 12.

According to the in-site geology survey of landslides, the stratigraphic parameters can be determined and shown in Table 1.

4.1.2. Rainfall Condition. Rainfall will increase the water content of the slope soil, leading to the reduction of the cohesive force and internal friction angle, furtherly causing slope instability. In order to model the most unfavourable 


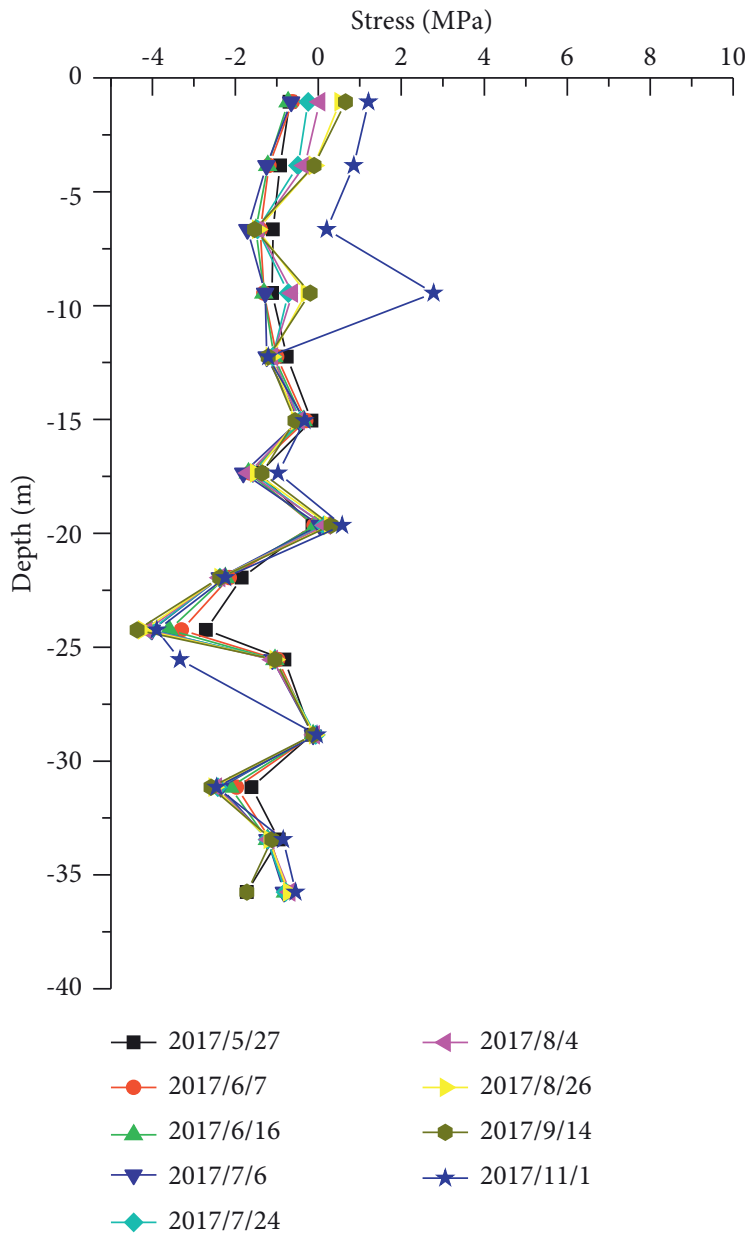

FIGURE 11: The body stress of 29\# antislide pile during the earthquake.

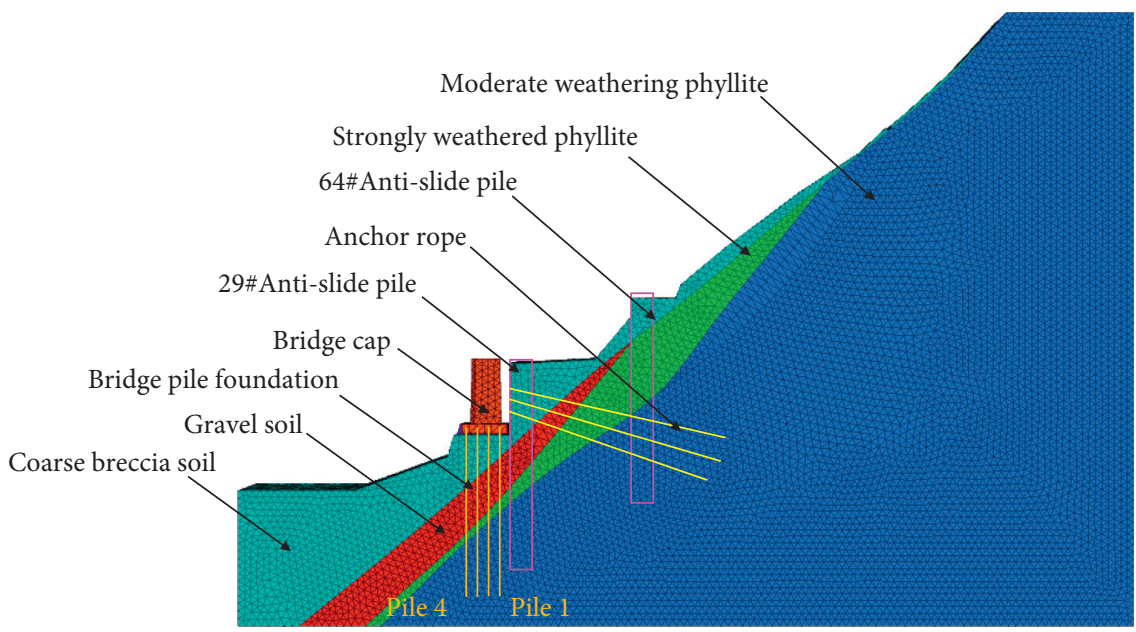

FIGURE 12: Numerical calculation model. 
TABle 1: Physical and mechanical parameters of landslide.

\begin{tabular}{lccccc}
\hline Material & Gravity $\left(\mathrm{kN} / \mathrm{m}^{3}\right)$ & Elastic modulus $(\mathrm{MPa})$ & Poisson's ratio & Cohesive force $(\mathrm{kPa})$ & Friction angle $\left(^{\circ}\right)$ \\
\hline Coarse breccia soil & 20 & 20 & 0.2 & 10 & 21 \\
Gravel soil & 21 & 40 & 0.2 & 17 & 24 \\
Strongly weathered phyllite & 24 & 500 & 0.18 & 45 & 30 \\
Moderate weathered phyllite & 25 & 1800 & 0.17 & 200 & 55
\end{tabular}

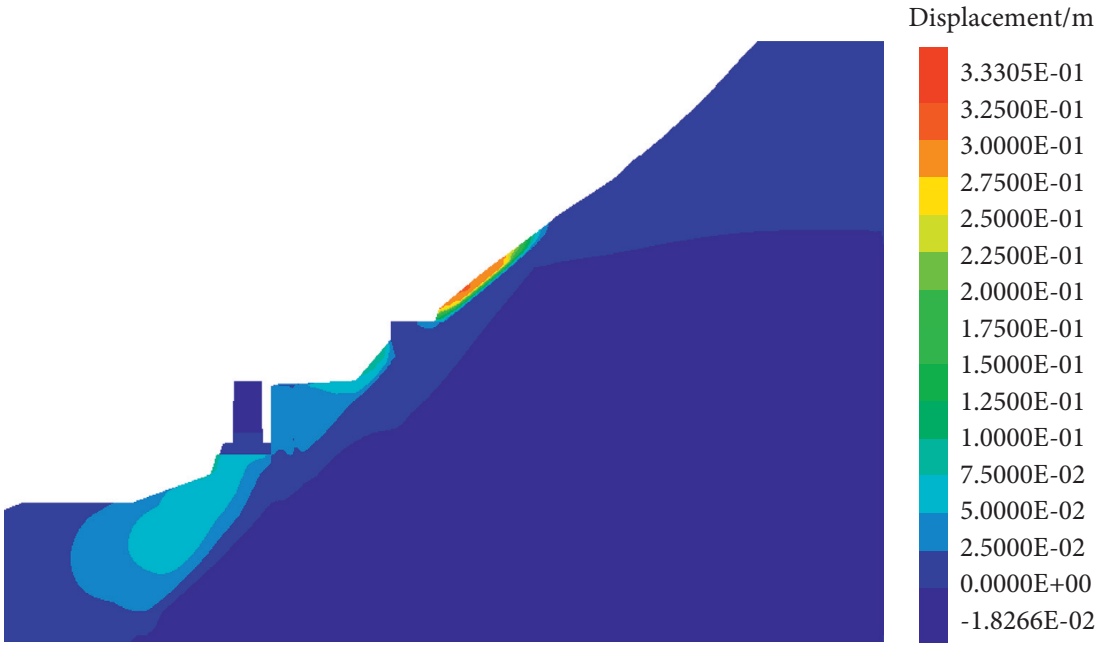

Figure 13: Cloud diagram of horizontal displacement of the slope.

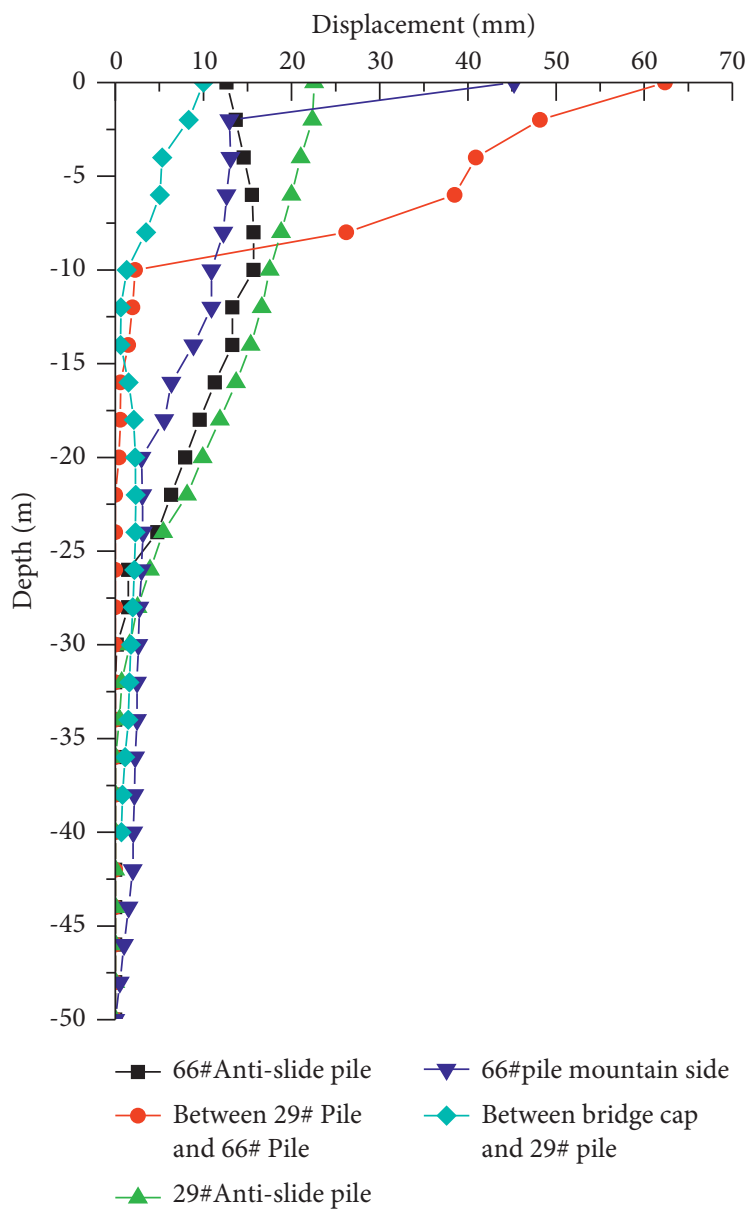

Figure 14: The deep displacement curve of the slope. 


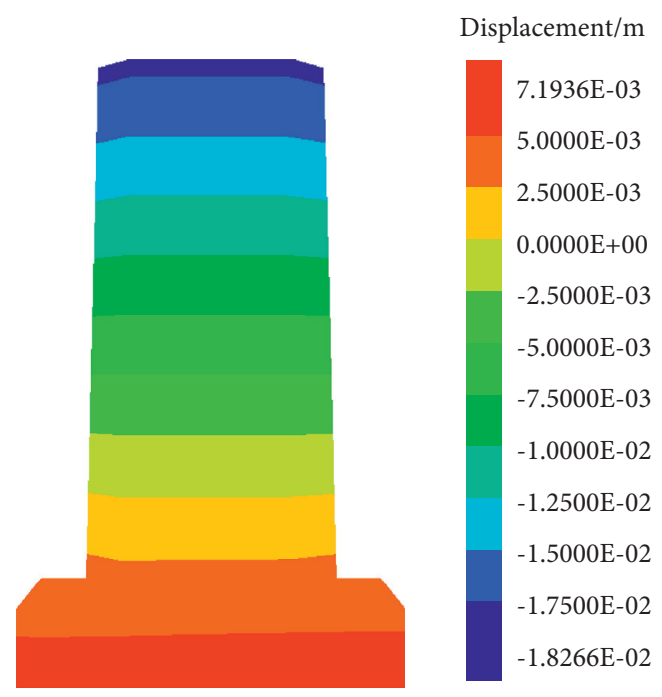

Figure 15: Cloud diagram of horizontal displacement of bridge cap.

conditions of extreme rainfall, the soil parameters when the soil is close to the saturated state were chosen.

4.1.3. Earthquake Condition. The quasistatic method was used to conduct seismic analysis of the slope, and the peak acceleration of the site vibration was $0.2 \mathrm{~g}$. A rare earthquake with a fortification intensity of 8 as the basic acceleration $\alpha$ of the horizontal earthquake, and the comprehensive horizontal earthquake coefficient $\alpha \mathrm{w}$ was taken as 0.05 .

\subsection{Numerical Calculation of Extreme Rainfall Condition}

4.2.1. The Analysis for the Simulate Displacement. As shown in Figures 13-15, under the same rainfall condition, there were three distinct areas showing deformation; among them, the deformation of the upper side area of $66 \#$ antislide piles was the most obvious, and the maximum displacement of soil was $330 \mathrm{~mm}$; between 29\# antislide piles, the maximum deformation was $27.2 \mathrm{~mm}$, and the soil between the 29\# antislide pile and the cap deformed $10.68 \mathrm{~mm}$, suggesting that under the action of rainfall, the slope produced landslide thrust, but the displacement gradually decreased because of the two rows of antislide piles. Simultaneously, the $29 \#$ antislide pile produced a squeezing effect on the soil on the riverside; thus, the remaining landslide thrust on the bridge cap caused the deformation of the bridge cap, and a $100 \mathrm{~mm}$ deformation occurred at the toe of the slope, indicating that the controlling deformation at the toe of the slope should be considered during the design of the support.

Under the comprehensive effects of the landslide thrust, the traction force from the riverside, the vertical bridge slab, and the vehicle gravity, the bridge cap occurred an overall inclined deformation, in which the top part moved $18.26 \mathrm{~mm}$ to the mountainside relative to the bottom part, and the bottom part moved $7.19 \mathrm{~mm}$ to the riverside, reaching $111.7 \%$ of the allowable lateral displacement limit of $16.35 \mathrm{~mm}$ in the "Code for Design of Railway Bridges and Culverts" [20], and seriously affects the safety of railway operations.

4.2.2. Stress Analysis of Bridge Pile Foundation. Under the condition of extreme rainfall, due to the decrease in the strength of the soil layer, the stress of the bridge pile foundation mainly showed the following characteristics in Figure 16.

The distribution of the bending moment of the bridge pile was closely related to the stratum. Under the combined effect of the remaining landslide thrust and the traction force of the slope toe, the distribution of the bending moment of each pile varied; among them, pile 2 and pile 3 showed the largest negative bending moment, and the maximum negative bending moment of pile 2 appeared at $14 \mathrm{~m}$ below the top of the pile, and the maximum negative bending moment of pile 3 appeared at $23 \mathrm{~m}$ below the top of the pile. From pile 1 to pile 4 , the position of the maximum negative bending moment continuously decreased with the bedrock of the slope.

Compared with ordinary bridge pile foundations, the bridge pile foundation on the high-steep slope has dual functions of load-bearing and sliding resistance. In the bridge design, the reinforcement of the side piles and the caps should be paid special attention. At the same time, the corresponding reinforcement design should be chosen according to the distribution characteristics of the bending moment of each pile.

\subsection{Numerical Calculation and Analysis of the Extreme Seismic Condition}

4.3.1. Analysis of Displacement Calculation Results. As shown in Figures 17-19, under the impact of seismic with the intensity of $8^{\circ}$, the slope deformation characteristics were 


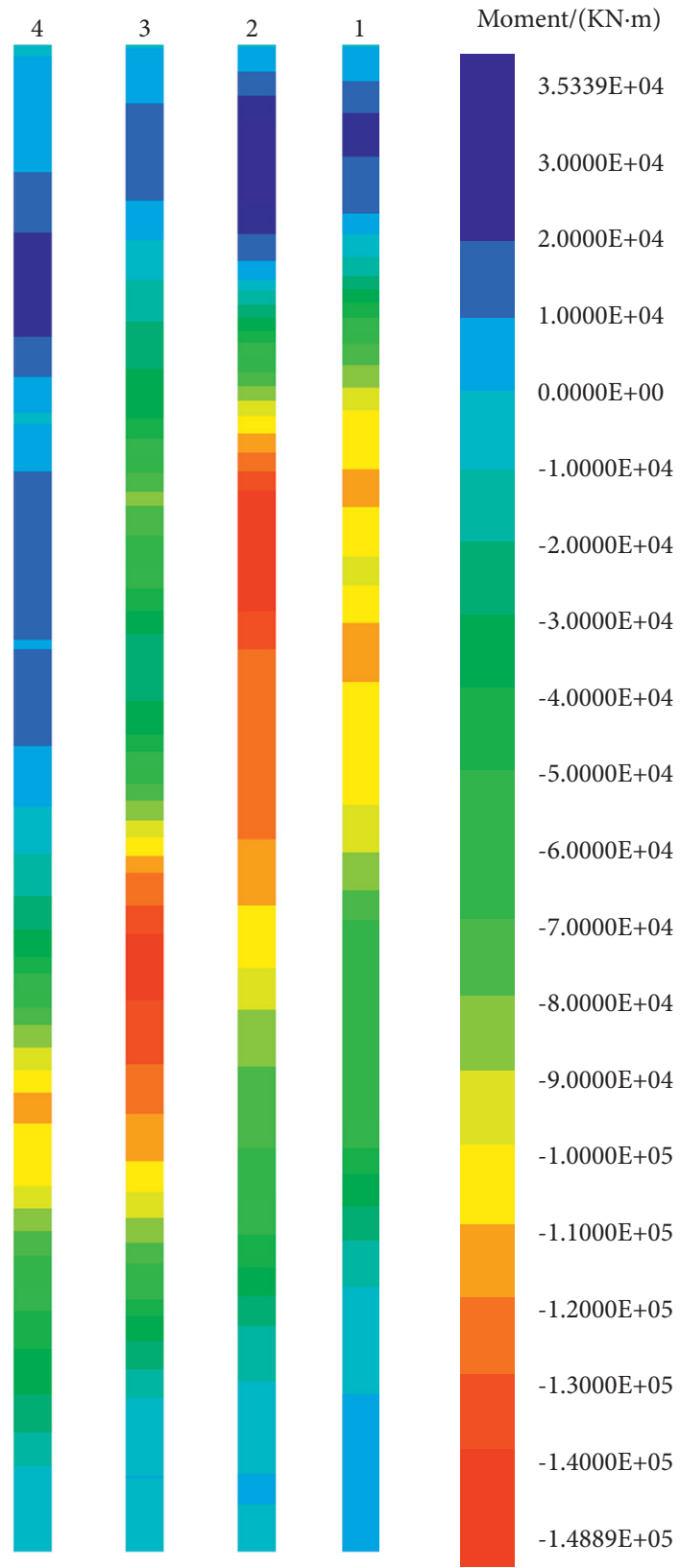

FIGURE 16: Cloud diagram of bending moment of bridge pile foundation.

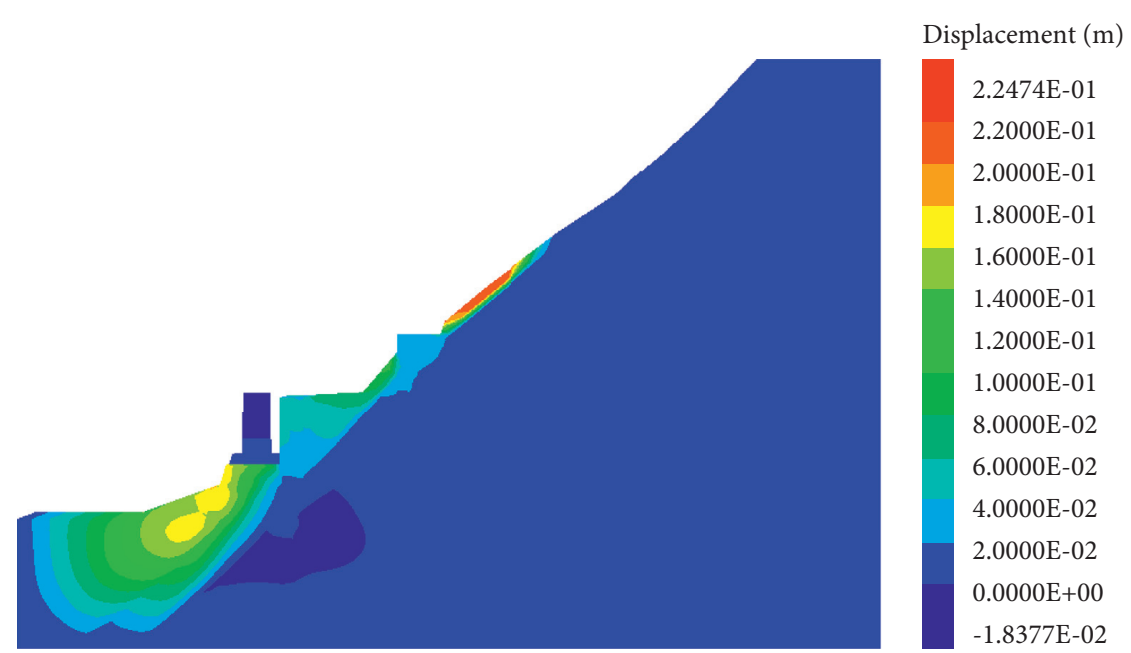

FIgURE 17: Cloud diagram of bending moment of bridge pile foundation. 


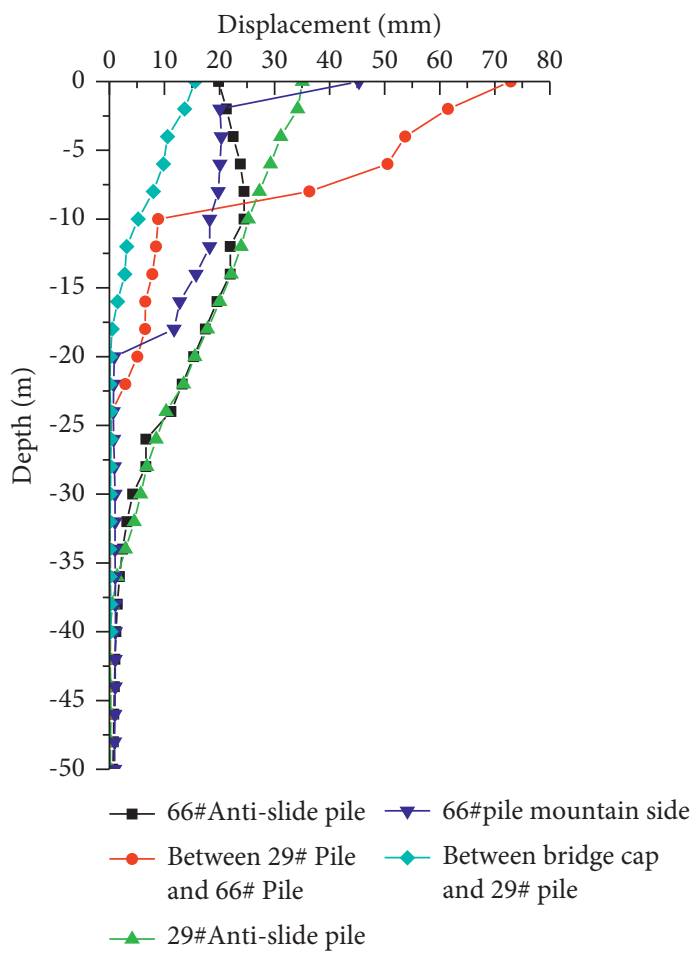

Figure 18: The displacement curve of the deep part of the slope.

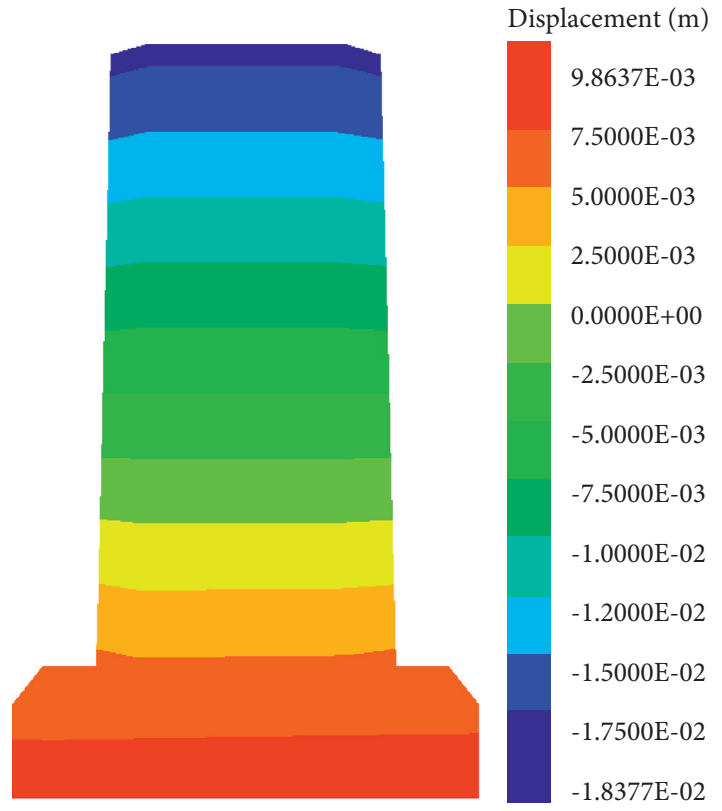

FIgURE 19: Cloud diagram of horizontal displacement of bridge cap.

similar to those under the extreme rainfall condition. The deformation of the upper side of the 66\# antislide pile was the most obvious with the maximum soil displacement of $224.7 \mathrm{~mm}$; the maximum deformation between the 29\# antislide piles was $40 \mathrm{~mm}$, and the soil between the 29\# antislide pile and the cap deformed $17 \mathrm{~mm}$; this indicates that under the function of two rows of antislide piles, the

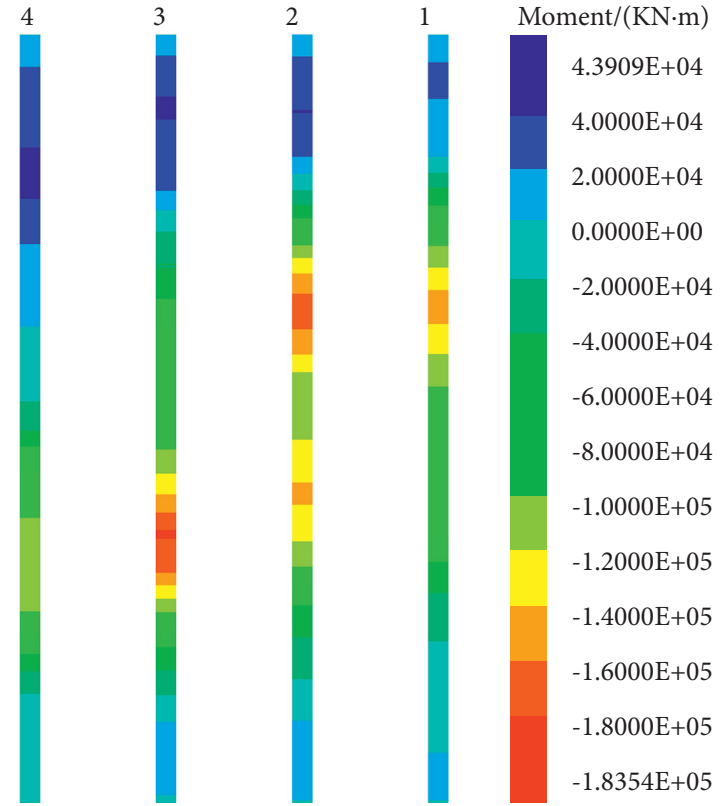

FIgURE 20: Cloud diagram of bending moment of bridge pile foundation.

remaining landslide thrust acting on the bridge cap caused the deformation of the bridge platform, as well as the $184 \mathrm{~mm}$ deformation at the slope toe.

Under the action of the earthquake, the bridge caps also showed an overall inclined deformation, in which the bottom part moved $9.86 \mathrm{~mm}$ to the riverside and the top part moved $18.37 \mathrm{~mm}$ to the mountainside, reaching $112.4 \%$ of 
the $16.35 \mathrm{~mm}$ lateral allowable displacement limit of the top of the bridge pier in the "Code for Design of Railway Bridges and Culverts" [20], which seriously affects the safety of railway operation.

4.3.2. Stress Analysis of Bridge Pile Foundation. Under the seismic intensity of 8 degrees, due to changes in the internal bridge structure of the rock mass, the stress of the bridge pile foundation mainly shows the following characteristics.

As shown in Figure 20, under the impact of the earthquake, the stress characteristics of the bridge pile foundation were more consistent with those under rainfall; the negative bending moment of pile 2 and pile 3 was the largest, the maximum negative bending moment of pile 2 appeared at $14 \mathrm{~m}$ below the top of the pile, and the maximum negative bending moment of pile 3 appeared at $24.5 \mathrm{~m}$ below the top of the pile. From pile 1 to pile 4, the position of the maximum negative bending moment continuously decreased.

\section{Conclusion and Discussion}

With a railway landslide body as the background, field monitoring tests and numerical analysis were carried out on high-steep slopes. The mechanism of the influence of the high-steep slope on the bridge structure was analyzed.

(1) Under the conditions of rainfall and earthquake, the original stress balance in the slope is broken, resulting in the continuous increase in the landslide thrust. Because of the existence of the supporting structure, the remaining landslide thrust causes the lower slope to produce compression and transmits squeeze force to the bridge structure. Under the effect of the remaining landslide thrust, the traction force of the slope toe and the vertical bridge slab and the gravity of the vehicle, the bridge cap declines and deforms.

(2) During the in-site monitorization, under the influence of rainfall and earthquake, the antislide pile and bridge structure deforms, but the force and deformation characteristics are not obvious, and the slope and bridge structure remains stable as a whole.

(3) Under extreme conditions such as rainfall and earthquakes, the deformation of the bridge pier and abutment exceeds the allowable limit of the lateral displacement of the pier top, reaching $111.7 \%$ $112.4 \%$ of the limit, which seriously affects the stability of the bridge structure and the safety of railway operations. The horizontal bearing capacity of the bridge structure is limited, and the deformation of the pier foundation is strictly required. In the design of the bridge pile foundation, the slip resistance of the bridge pile foundation can be increased by increasing the pile diameter, and the deformation of the bridge cap can be reduced.

(4) The bridge structure at the foot of the high-steep slope is affected by the combined effect of the landslide thrust and the traction force of the slope toe. While designing the support structure, not only the landslide thrust of the slope should be considered but also the traction force from the slope toe.

\section{Data Availability}

The data used to support the findings of this study are available from the corresponding author upon request.

\section{Conflicts of Interest}

The authors declare that they have no conflicts of interest.

\section{Acknowledgments}

This research was funded by National Key R\&D Program of China (No. 2018YFC1504902), China Railway Corporation Research and Development of Science and Technology Plan Project (No. P2018G001), and National Railway Group Science and Technology Research and Development Program (No. N2020G052).

\section{References}

[1] H. Luo, "Research on effect of heap loading on deformation and mechanical properties of bridge double pile foundation on steep slope," Open Journal of Civil Engineering, vol. 10, no. 2, pp. 117-130, 2020.

[2] L. Sun, Research on Calculation and Analysis Method of Bridge Group Pile Foundation in Slope Section with Poor Stability, Southwest Jiaotong University, Chengdu, China, 2019.

[3] Q. Chang, Research on the Interaction between Steep Slope and Bridge Pile Foundation under Earthquake, Jiangxi University of Science and Technology, Ganzhou, China, 2019.

[4] Y. Zhang, J. Tang, Z. He, and J. Tan, "A novel displacement prediction method using gated recurrent unit model with time series analysis in the Erdaohe landslide," Natural Hazards, vol. 105, 2020.

[5] Y. Zhang, Z. Zhang, and S. Xue, "Stability analysis of a typical landslide mass in the Three Gorges Reservoir under varying reservoir water levels," Environmental Earth Sciences, vol. 79, no. 1, 2020.

[6] D. Qing, "Three-dimensional finite element method for slope stability evaluation under bridge foundation load," Highway Engineer, vol. 34, no. 3, pp. 38-42, 2008.

[7] M. Zhao, P. Yin, M. Yang, and Y. Li, "Analysis of mechanical characteristics and influencing factors of bridge pile foundations on high and steep slopes," Journal of Central South University, vol. 43, no. 7, pp. 2733-2739, 2012.

[8] W. Zhao, Q. Xie, and Y. Li, "Study on the safety distance of bridge foundation on high and steep slope," Journal of Railway Engineering Society, vol. 23, no. 6, pp. 47-50, 2006.

[9] H. Lassaad, N. Hussien Mahmoud, and K. Mourad, "On the behaviour of pile groups under combined lateral and vertical loading," Ocean Engineering, vol. 131, pp. 174-185, 2017.

[10] M. N. Hussien, T. Tobita, S. Iai, and M. Karray, "On the influence of vertical loads on the lateral response of pile foundation," Computers and Geotechnics, vol. 55, pp. 392403, 2014.

[11] Y. El-Mossallamy, "Pile group action under vertical compression loads," Advances in Soil Mechanics and Geotechnical Engineering, IOS Press, Amsterdam, Netherlands, 2014. 
[12] C. Wang, Research on the Mechanical Behavior of Three-Dimensional High Slope Rock Mass and the Determination of the Location of the Bridge Foundation under the Load of the Bridge Foundation, Southwest Jiaotong University, Chengdu, China, 2008.

[13] Z. Li, G. Quan, D. Liu et al., "Experimental study on horizontal load of soil slope building pile foundation," Chinese Journal of Rock Mechanics and Engineering, vol. 23, no. 6, pp. 930-935, 2004.

[14] O. Reul and M. F. Randolph, "Design strategies for piled rafts subjected to nonuniform vertical loading," Journal of Geotechnical and Geoenvironmental Engineering, vol. 130, no. 1, pp. 1-10, 2004

[15] M. Gennaro, A. Osouli, Z. Siavash, and I. Shafii, "Performance of a pier group foundation in swelling rock," Geotechnical \& Geological Engineering, vol. 32, no. 1, pp. 197-204, 2014.

[16] G. Konstantinos, M. Georgiadis, and C. Anagnostopoulos, "Lateral bearing capacity of rigid piles near clay slopes," Soils and Foundations, vol. 53, no. 1, pp. 144-154, 2013.

[17] M. Zhao, C. Yang, M. Yang et al., "Force analysis of bridge foundation piles in steep slope section based on finite pole element method," China Journal of Highway and Transport, vol. 27, no. 6, pp. 51-58, 2014.

[18] X. Gong, M. Yang, M. Zhao et al., "Model test of bearing mechanism of bridge pile foundation in high and steep transverse slope section in mountainous area," China Journal of Highway and Transport, vol. 26, no. 2, pp. 56-62, 2013.

[19] B. Yuan, K. Xu, Y. Wang, and R. Chen, "Investigation of deflection of a laterally loaded pile and soil deformation using the PIV technique," International Journal of Geomechanics, vol. 14, no. 1, pp. 1-7, 2014.

[20] The Third Railway Survey and Design Institute Group Co. Ltd, TB 10002-2017, Code for Design of Railway Bridges and Culverts, Railway Publishing House, Beijing China, 2017. 